\title{
Continuous relationships between non-diabetic hyperglycaemia and both cardiovascular disease and all-cause mortality: the Australian Diabetes, Obesity, and Lifestyle (AusDiab) study
}

\author{
E. L. M. Barr • E. J. Boyko • P. Z. Zimmet • R. Wolfe •
}

A. M. Tonkin • J. E. Shaw

Received: 11 July 2008 / Accepted: 2 December 2008 /Published online: 8 January 2009

(C) Springer-Verlag 2008

\begin{abstract}
Aims/hypothesis Hyperglycaemia is a risk factor for cardiovascular disease (CVD) and all-cause mortality in individuals without diabetes. We investigated: (1) whether the risk of allcause and CVD mortality extended continuously throughout the range of fasting plasma glucose (FPG), $2 \mathrm{~h}$ plasma glucose (2hPG) and $\mathrm{HbA}_{1 \mathrm{c}}$ values; and (2) the ability of these measures to improve risk prediction for mortality.

Methods Data on 10,026 people aged $\geq 25$ years without diagnosed diabetes were obtained from the population-based Australian Diabetes, Obesity and Lifestyle study. Between 1999 and 2000, FPG, 2 hPG and $\mathrm{HbA}_{1 \mathrm{c}}$ were assessed and allcause (332 deaths) and CVD (88 deaths) mortality were obtained after 7 years.

Results Both $2 \mathrm{hPG}$ and $\mathrm{HbA}_{1 \mathrm{c}}$ exhibited linear relationships with all-cause and CVD mortality, whereas FPG showed Jshaped relationships. The adjusted HR (95\% CI) for all-cause mortality per SD increase was $1.2(1.1-1.3)$ for $2 \mathrm{hPG}$ and 1.1 (1.0-1.2) for $\mathrm{HbA}_{1 \mathrm{c}}$. The HR for FPG $<5.1 \mathrm{mmol} / \mathrm{l}$ (per SD decrease) was 2.0 (1.3-3.0); for $\mathrm{FPG} \geq 5.1 \mathrm{mmol} / 1$ (per $\mathrm{SD}$ increase) the HR was $1.1(1.0-1.2)$. Corresponding HRs for CVD mortality were 1.2 (1.0-1.4), 1.2 (1.0-1.3), 4.0 (2.17.6) and 1.3 (1.1-1.4). The discriminative ability of each

E. L. M. Barr $(\bowtie) \cdot$ E. J. Boyko $\cdot$ P. Z. Zimmet · J. E. Shaw Baker IDI Heart and Diabetes Institute,

250 Kooyong Road,

Caulfield 3162 VIC, Australia

e-mail: Elizabeth.Barr@bakeridi.edu.au

E. L. M. Barr • P. Z. Zimmet • R. Wolfe • A. M. Tonkin •

J. E. Shaw

Department of Epidemiology and Preventive Medicine,

Monash University,

Melbourne, VIC, Australia
\end{abstract}

measure was similar; no measure substantially improved individual risk identification over traditional risk factors. Conclusions/interpretation In individuals without diagnosed diabetes, $2 \mathrm{hPG}$ and $\mathrm{FPG}$, but not $\mathrm{HbA}_{1 \mathrm{c}}$ were significant predictors of all-cause mortality, whereas all measures were significant predictors of CVD mortality. However, these glucose measures did not substantially improve individual risk identification.

Keywords Cardiovascular disease · Diabetes ·

Hyperglycaemia $\cdot$ Mortality

$\begin{array}{ll}\text { Abbreviations } \\ \text { AusDiab } & \begin{array}{l}\text { Australian Diabetes, Obesity and Lifestyle } \\ \text { CVD }\end{array} \\ \text { cardiovascular disease } \\ \text { DECODE } & \begin{array}{l}\text { Diabetes Epidemiology: Collaborative } \\ \text { Analysis Of Diagnostic Criteria in Europe }\end{array} \\ & \text { fasting plasma glucose } \\ \text { GHb } & \text { total glycated haemoglobin } \\ \text { 2hPG } & 2 \text { h plasma glucose } \\ \text { IDI } & \text { integrated discrimination improvement } \\ \text { NDI } & \text { Australian National Death Index } \\ \text { NRI } & \text { net reclassification improvement }\end{array}$

\section{Introduction}

Uncertainty remains regarding the relationship between glycaemia and each of mortality and cardiovascular disease (CVD), especially below the diagnostic threshold for diabetes [1-5]. The continuous relationships between blood glucose and all-cause or CVD mortality have been described as threshold [6, 7], continuous [8, 9] and J-shaped [10, 11]. For 
CVD risk, all meta-analyses report a graded continuous relationship for post-load blood glucose [3, 4, 12]. However, for fasting blood glucose, a graded continuous relationship [3], a J-shaped relationship [12] and a threshold relationship [4] have been reported. The Diabetes Epidemiology: Collaborative Analysis Of Diagnostic Criteria in Europe (DECODE) study [12] evaluated all-cause mortality and reported J-shaped relationships for fasting and post-load blood glucose. However, limitations of these meta-analyses include: (1) the component studies used different blood sample types (e.g. whole blood or plasma) and different glucose assays [3, 4, 12]; (2) failure to fully adjust for concomitant CVD risk factors [3, 4]; (3) lack of data on women [3, 12]; and (4) no data on the nature of the continuous relationships for $\mathrm{HbA}_{1 \mathrm{c}}$ $[3,4,12]$. Furthermore, the findings from these meta-analyses may have limited relevance to contemporary populations as baseline data from the component studies were collected up to 20 years ago $[3,4,12]$.

Both fasting and post-load blood glucose, and $\mathrm{HbA}_{1 \mathrm{c}}$ reflect different glycaemic metabolic processes [13], potentially leading to different associations with mortality and CVD. In people without diagnosed diabetes, some studies report that fasting blood glucose is associated with all-cause and CVD mortality [4, 8, 14], whereas others report that post-load blood glucose is more strongly related to these outcomes than fasting blood glucose $[3,12,15]$. $\mathrm{HbA}_{1 \mathrm{c}}$ has also been found to be associated with subsequent CVD [7, 16-18]. Only a few studies have compared all three glycaemic indices in the same population [19-22], with all but one [19] indicating that $2 \mathrm{~h}$ blood glucose was most strongly associated with all-cause mortality and/or CVD [20-22]. However, these latter studies were undertaken in men only [22], in middle- to older-aged adults [19, 20, 22] or analysed total glycated haemoglobin $(\mathrm{GHb})$ rather than $\mathrm{HbA}_{1 \mathrm{c}}$ [19]. Therefore, they may not be generalisable to the wider population. Furthermore, these studies did not comprehensively assess the nature of the relationships between each glucose measure and the outcomes of interest or the contribution of the different glucose measures to individual risk discrimination for total and CVD mortality risk [19-22].

Developing a better understanding of the magnitude and nature of these relationships, as well as evaluating the extent to which glucose contributes to individual risk stratification would elucidate the potential benefit of glucose control among persons without diabetes and indicate which, if any, measure of glycaemia is the most appropriate for prediction of mortality in the general population. Accordingly, this study used 7 year follow-up data from a cohort of 10,026 people aged $\geq 25$ years without previously diagnosed diabetes, who participated in the Australian Diabetes, Obesity and Lifestyle (AusDiab) Study to examine: (1) the nature and strength of the relationships between each of fasting plasma glucose (FPG), $2 \mathrm{~h}$ post-load plasma glucose (2hPG) and $\mathrm{HbA}_{1 \mathrm{c}}$, and CVD and all-cause mortality; and (2) whether any of the glucose measures improved prediction of CVD and all-cause mortality beyond that achieved by traditional risk factors.

\section{Methods}

Study design and population AusDiab is a national Australian prospective population-based cohort study. Baseline measurements were collected from 1999 to 2000 on 11,247 non-institutionalised men and women aged $\geq 25$ years. Detailed methods have been previously described [23]. Briefly, individuals were recruited from 42 randomly selected census districts, six in each state and in the Northern Territory. From the 17,129 eligible households, 20,347 individuals completed a household interview and 11,247 (55.3\%) had a biomedical examination, giving an overall response rate of $37 \%$. Participants were excluded if at baseline they had previously known diabetes $(n=475$; based on self-reported physiciandiagnosed diabetes with use of hypoglycaemic medication or FPG $\geq 7.0 \mathrm{mmol} / 1$ or $2 \mathrm{hPG} \geq 11.1 \mathrm{mmol} / \mathrm{l})$, had not fasted for $\geq 9 \mathrm{~h}(n=18)$, were pregnant $(n=60)$ or had missing values for FPG $(n=1), 2 \mathrm{hPG}(n=125), \mathrm{HbA}_{1 \mathrm{c}}(n=61)$ or other covariates included in the analyses $(n=475)$. Six participants who died could not be matched to the Australian National Death Index (NDI) and were also excluded. Thus, these analyses were undertaken in 10,026 participants. All participants gave informed consent, and ethics approval was provided by the Ethics Committees of the International Diabetes Institute, Monash University and the Australian Institute of Health and Welfare.

Measurements Data on age, sex, use of anti-hypertensive and lipid-lowering medications, history of CVD (angina, myocardial infarction or stroke) and smoking (never, ex- or current smoker) were collected by interview. Measurements included blood pressure [24], anthropometrics [25] and a 75 g OGTT. Values for FPG, 2hPG, fasting serum total cholesterol, triacylglycerol and HDL-cholesterol were measured using an analyser (AU600; Olympus Optical, Tokyo, Japan). GHb was measured from frozen samples of whole blood collected in EDTA tubes and stored at $-70^{\circ} \mathrm{C}$ for $2-36$ months, using high performance liquid chromatography (Bio-Rad Variant Hemoglobin Testing System; Bio-Rad, Hercules, CA, USA) with standardised conversion to $\mathrm{HbA}_{1 \mathrm{c}}$ (normal range 4.2$6.3 \%$ ). Previous studies have confirmed the stability of $\mathrm{HbA}_{1 \mathrm{c}}$ in samples stored for 56 weeks [26]. A validation study conducted on AusDiab samples $(n=17)$ compared $\mathrm{HbA}_{1 \mathrm{c}}$ values on samples stored for 5 months with the results from the same samples after storage for 26 months. The mean (maximum) difference was $0.03(0.2)$ percentage points. 
Follow-up and outcomes Follow-up for all-cause mortality was to the date of death or 1 June 2006, whichever occurred first. As there is a delay between obtaining vital status data and cause of death information from the NDI, the period of follow-up for CVD and non-CVD mortality was up to the date of death or 5 December 2005. Deaths due to non-CVD causes are a competing risk for CVD mortality and therefore, the associations between the glucose indices and non-CVD mortality were also explored. Mortality status, as well as underlying and contributory causes of death were determined by linking the AusDiab cohort to the NDI using methods previously described [2]. The accuracy of the NDI for ascertainment of vital status and CVD deaths has been established [27]. People who were not matched to the NDI were assumed to be alive. Deaths were attributed to CVD if the underlying cause of death was coded I10-I25, I46.1, I48, I50-I99 or R96 according to the 2006 International Classification of Diseases 10th revision (ICD-10; http://www.who.int/classifi cations/icd/en/). In cases where the underlying cause of death was uncomplicated diabetes (E109, E119 or E149) or unspecified hyperlipidaemia (E785), CVD was considered to be the cause of death $(n=2)$ if any of the CVD codes (I10-I25, I46.1, I48, I50-I99 or R96) were recorded in the first position on the death certificate.

Statistical analysis $\mathrm{FPG}, 2 \mathrm{hPG}$ and $\mathrm{HbA}_{1 \mathrm{c}}$ were analysed as categorical and continuous variables.

First, FPG, $2 \mathrm{hPG}$ and $\mathrm{HbA}_{1 \mathrm{c}}$ were classified into quintiles. The upper quintiles of FPG and $2 \mathrm{hPG}$ were further divided to reflect the American Diabetes Association [28] or WHO [29, 30] criteria for impaired fasting glucose, impaired glucose tolerance and diabetes. Unadjusted mortality rates $(95 \% \mathrm{CI})$ per 1,000 person-years were calculated for each category of FPG, $2 \mathrm{hPG}$ and $\mathrm{HbA}_{1 \mathrm{c}}$. To test differences in means and proportions for baseline characteristics between the categories of FPG, $2 \mathrm{hPG}$ and $\mathrm{HbA}_{1 \mathrm{c}}$, one-way analysis of variance and $\chi^{2}$ test analyses were used, respectively. Continuous covariates with skewed distributions were logarithmically transformed prior to analysis.

Second, the nature of the continuous relationships between each glucose measure and all-cause, CVD and non-CVD mortality was evaluated by comparing age- and sex-adjusted Cox proportional hazard models fitted with a linear term only to models with linear plus quadratic terms, linear plus quadratic plus cubic terms and linear plus log-transformed terms. These nested models were compared using loglikelihood ratio tests. In addition, piecewise linear splines, which do not assume a particular functional form between the exposure and outcome [31], were also used to explore nonlinear relationships between each glucose measure and allcause, CVD and non-CVD mortality. For each measure, the simplest model with the lowest Akaike's Information
Criterion (AIC) [32] was deemed to be the best and was used in subsequent analyses.

Covariates achieving $p<0.25$ in univariate analysis or those considered to be important confounders were entered into the multivariate model. Final models were adjusted for reported history of CVD, smoking, diastolic blood pressure (which showed a stronger association with all-cause and CVD mortality than did systolic blood pressure), waist-to-hip ratio, use of lipid-lowering medication, total cholesterol and triacylglycerol (which showed stronger associations with the outcomes than HDL). In order to compare the strength of the associations between the glucose measures and mortality outcomes, HRs and 95\% CIs for each of the glucose measures were expressed per 1 SD. Correlations between blood glucose measures, and between blood glucose measures and other covariates were assessed with Pearson's or Spearman's correlation coefficients. There was no evidence of multicollinearity between covariates for any of the fitted models (variance inflation factor $<4$ for all independent variables) [33].

Interactions between each glucose measure and sex, age and history of CVD were tested using log-likelihood ratio tests of models containing the variables as single terms nested within models including the first-order interactions. Stratified analyses according to sex were conducted for allcause mortality but not for cause-specific mortality, because there were fewer deaths.

Proportional hazards assumptions were satisfied for the three principal measures as assessed with graphs of $\log -\log$ plots of the relative hazards by time for discrete variables and by scaled Schoenfeld residuals.

Log-likelihood ratio statistics tested whether the addition of FPG, $2 \mathrm{hPG}$ or $\mathrm{HbA}_{1 \mathrm{c}}$ to a model with only age, sex and other covariates improved model performance, and whether the predictive effect of each multivariate-adjusted model including FPG, $2 \mathrm{hPG}$ and $\mathrm{HbA}_{1 \mathrm{c}}$ alone was influenced by adding $2 \mathrm{hPG}$ or $\mathrm{HbA}_{1 \mathrm{c}}$, FPG or $\mathrm{HbA}_{1 \mathrm{c}}$, and FPG or 2hPG, respectively.

The ability of FPG, $2 \mathrm{hPG}$ or $\mathrm{HbA}_{1 \mathrm{c}}$ to identify individual 5 year all-cause and CVD mortality risk was evaluated using the c-statistic, the net reclassification improvement (NRI) and integrated discrimination improvement (IDI) [34]. The c-statistic is obtained by considering all possible pairings of participants with and without the outcome and is equal to the proportion of those pairs in which the participant with the outcome has a higher glucose value than the person surviving. It ranges from 0.5 (poor discrimination) to 1.0 (perfect discrimination). A 0.01 increment corresponds to an additional $1 \%$ of pairs where the member of the pair experiencing the outcome has the higher glucose value. The NRI and IDI measures assume that any increases in predicted probabilities for an event due to an improved model for risk are only beneficial among those who experienced an event, whereas any decreases in 


\begin{tabular}{|c|c|c|c|c|}
\hline & 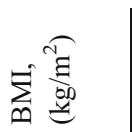 & 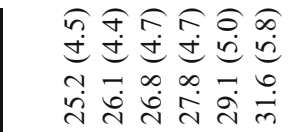 & 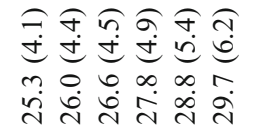 & 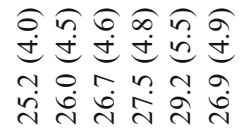 \\
\hline & $\frac{\mathscr{1}}{3}$ & 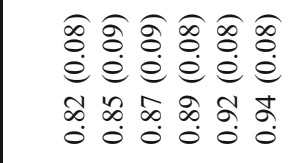 & 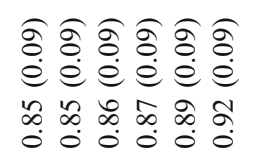 & 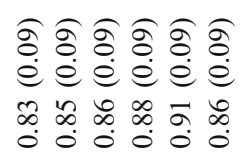 \\
\hline & 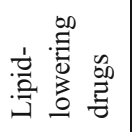 & 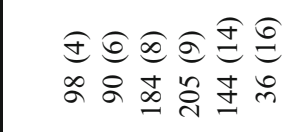 & 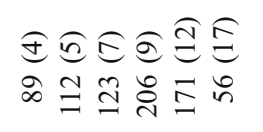 & 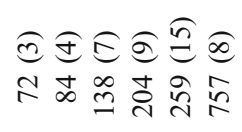 \\
\hline & 突 & 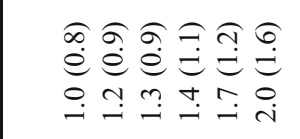 & 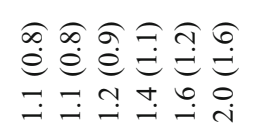 & 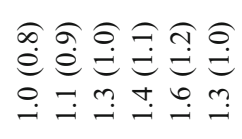 \\
\hline & 音 & 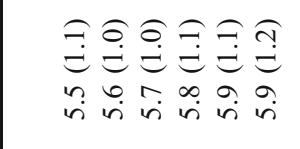 & 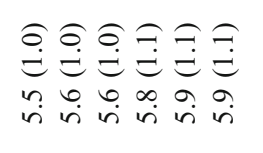 & 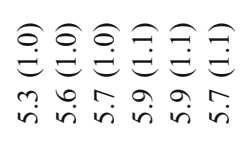 \\
\hline & 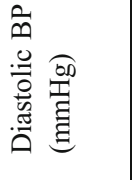 & 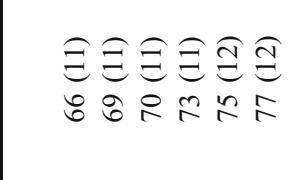 & 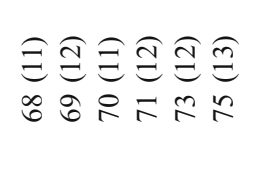 & 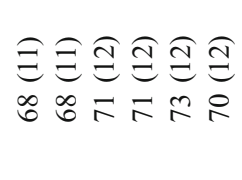 \\
\hline & 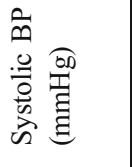 & 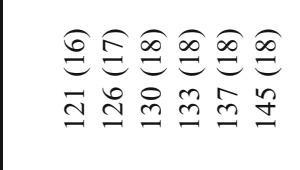 & 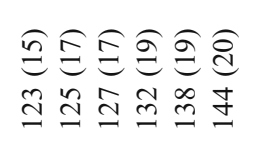 & 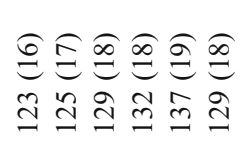 \\
\hline & 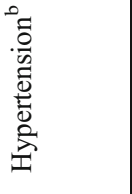 & 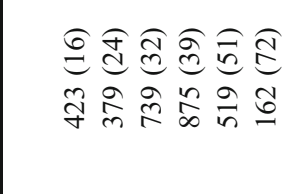 & 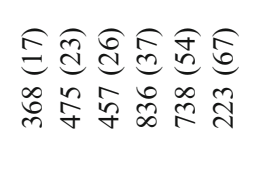 & 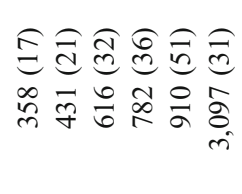 \\
\hline & 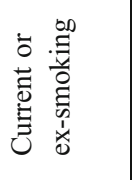 & 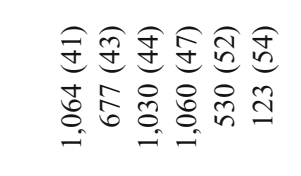 & 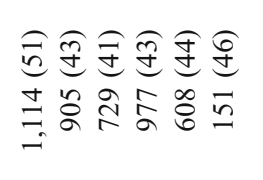 & 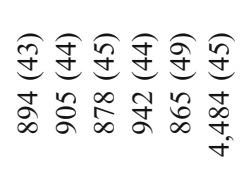 \\
\hline & 氛 & 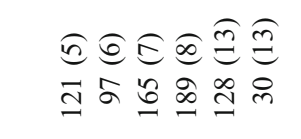 & 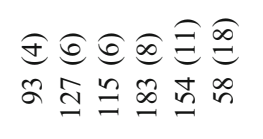 & 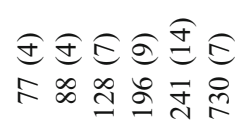 \\
\hline & $\frac{0}{\frac{\pi}{\pi}}$ & 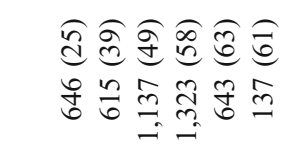 & 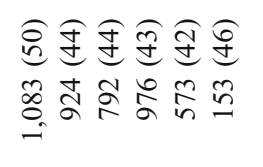 & 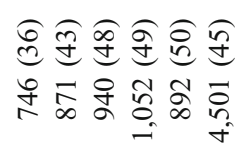 \\
\hline & 品 & 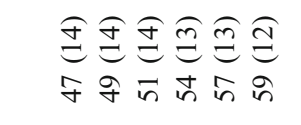 & 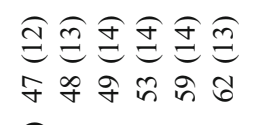 & 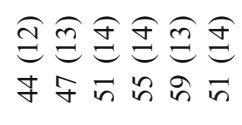 \\
\hline & 窇 & 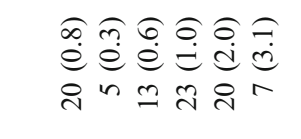 & 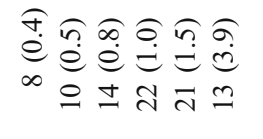 & 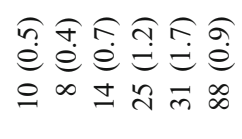 \\
\hline & 号 & 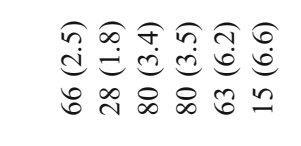 & 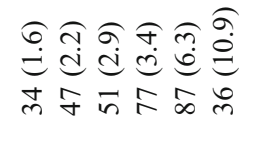 & 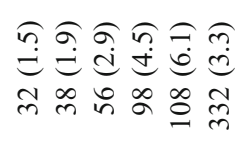 \\
\hline & $=$ & 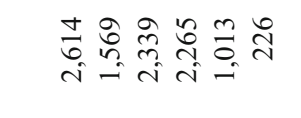 & 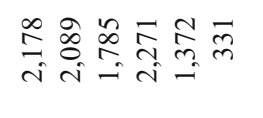 & 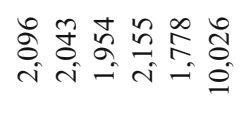 \\
\hline & 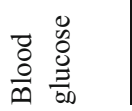 & 苛 $\vec{i} \frac{1}{\dot{v}}$ & $\infty$ & $a$ \\
\hline
\end{tabular}

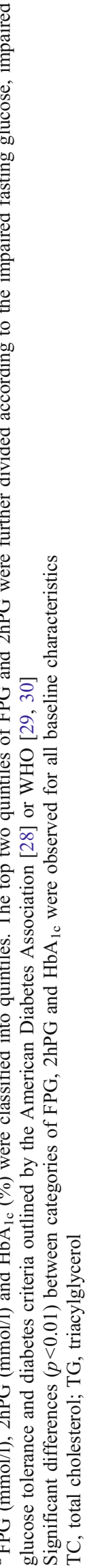



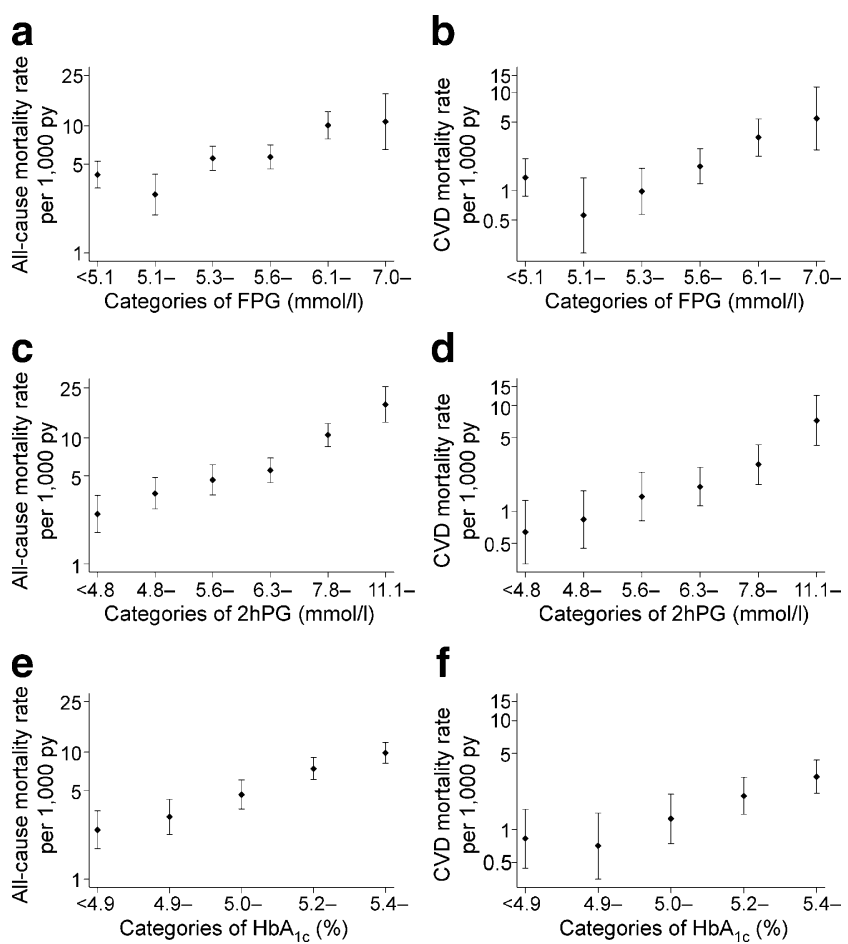

Fig. 1 Unadjusted all-cause and CVD mortality rates per 1,000 personyears (py) $(95 \% \mathrm{CI})$ for FPG (a, b), $2 \mathrm{hPG}(\mathbf{c}, \mathbf{d})$ and $\mathrm{HbA}_{1 \mathrm{c}}(\mathbf{e}, \mathbf{f})$ in individuals without previously diagnosed diabetes - the AusDiab study ( $y$-axis in logarithmic scale)

predicted probabilities due to the improved model are only beneficial for risk prediction among those who did not experience an event. The NRI was used to evaluate the extent to which different models reclassified individuals across three a priori categories $(0-<10 \%, 10-<20 \%$ and $\geq 20 \%)$ of 5 year predicted CVD death risk, as used previously in CVD risk prediction scores $[35,36]$. The IDI examines the change in estimated predicted probabilities as a continuous measure and was used to evaluate 5 year predicted all-cause and CVD death risks. Bootstrap methods were used to derive $95 \%$ CIs for the NRI and IDI estimates, and were based on 1,000 replications. Bootstrap replicates in which parameters of interest could not be estimated or were on the boundary of the parameter space were ignored. Analyses were conducted with Stata Statistical Software version 9.2 (StataCorp, College Station, TX, USA).

Fig. 2 Relative hazards for allcause mortality (solid lines) and CVD mortality (dashed lines) according to FPG (a), 2hPG (b) and $\mathrm{HbA}_{1 \mathrm{c}}$ (c) after adjusting for age and sex in individuals without previously diagnosed diabetes - the AusDiab study ( $y$-axis in logarithmic scale)

\section{Results}

Table 1 shows that for participants without diagnosed diabetes at baseline, CVD risk generally increased with increasing $\mathrm{FPG}, 2 \mathrm{hPG}$ and $\mathrm{HbA}_{1 \mathrm{c}}$.

There were 332 deaths (190 in men) after a median followup of 6.2 years, and 88 CVD deaths (56 in men) and 204 nonCVD deaths ( 119 in men) after a median of 5.7 years. Cause of death was available from the NDI for 292 of the 332 deaths: neoplasms $(n=125)$, atherosclerotic CVD $(n=88)$, respiratory disease $(n=22)$, nervous system diseases $(n=8)$, kidney disease $(n=6)$, poisoning $(n=6)$, other heart diseases $(n=6)$, gastrointestinal disease $(n=5)$, accidents $(n=4)$ and other causes $(n=22)$. Figure 1 shows that crude all-cause and CVD mortality rates increased with increasing FPG, $2 \mathrm{hPG}$ and $\mathrm{HbA}_{1 \mathrm{c}}$ levels. After adjusting for age and sex, a linear relationship best described the association between both 2hPG and $\mathrm{HbA}_{1 \mathrm{c}}$ and all-cause and CVD mortality, whereas a J-shaped relationship based on a two-slope spline model with a knot at $5.1 \mathrm{mmol} / \mathrm{l}$ (cut-point of second quintile) best described the association between FPG and both all-cause and CVD mortality (Fig. 2). Therefore, all subsequent analyses for $2 \mathrm{hPG}$ and $\mathrm{HbA}_{1 \mathrm{c}}$ were based on linear models and FPG analyses were based on the two-slope spline model.

Adjustment for other covariates did not greatly attenuate the all-cause and CVD mortality relationships for the glucose measures. FPG and 2hPG remained significant predictors of all-cause mortality, while $\mathrm{HbA}_{1 \mathrm{c}}$ showed borderline significance $(p=0.06)$. All glucose measures were significant predictors of CVD mortality (Table 2). For non-CVD mortality, $2 \mathrm{hPG}$ was a significant predictor (HR per SD increase was $1.1,95 \%$ CI $1.0-1.2)$, but FPG and $\mathrm{HbA}_{1 \mathrm{c}}$ were not significant predictors after adjusting for age and sex (data not shown). Further adjustment for smoking, waist-to-hip ratio and history of CVD did not attenuate the association between $2 \mathrm{hPG}$ and non-CVD mortality.

Age and history of CVD were not significant effect modifiers of the relationships between both FPG and 2hPG and all-cause mortality, but significant interactions were observed between FPG and sex ( $p=0.03)$, and $2 \mathrm{hPG}$ and sex $(p=0.02)$. Sex-stratified analyses revealed that the relative risk of all-cause mortality per SD $(0.7 \mathrm{mmol} / \mathrm{l})$ decrease in FPG $<5.1 \mathrm{mmol} / \mathrm{l}$ was greater in men. The relative risk of all-

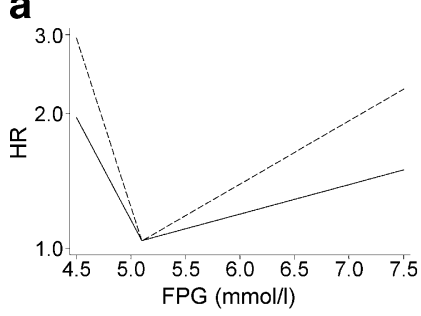

b

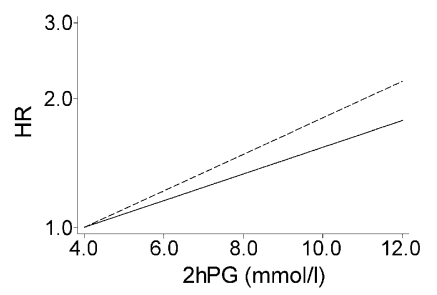

C

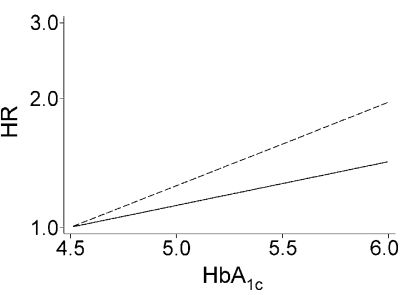


Table 2 Risk of all-cause and CVD mortality according to FPG, $2 \mathrm{hPG}$ and $\mathrm{HbA}_{1 \mathrm{c}}$ in individuals without diagnosed diabetes - the AusDiab study

\begin{tabular}{|c|c|c|c|c|}
\hline \multirow[t]{2}{*}{ Blood glucose measure (per SD) ${ }^{\mathrm{ac}}$} & \multicolumn{2}{|c|}{ Age- and sex-adjusted } & \multicolumn{2}{|c|}{ Multivariate-adjusted $^{\mathrm{b}}$} \\
\hline & HR & $95 \% \mathrm{CI}$ & HR & $95 \%$ CI \\
\hline \multicolumn{5}{|l|}{ All cause mortality } \\
\hline \multicolumn{5}{|l|}{ FPG (two-slope spline) $)^{\mathrm{a}}$} \\
\hline$<5.1$ & 2.1 & $1.4-3.3 *$ & 2.0 & $1.3-3.0 *$ \\
\hline$>5.1$ & 1.1 & $1.0-1.2 *$ & 1.1 & $1.0-1.2 *$ \\
\hline $2 \mathrm{hPG}^{\mathrm{c}}$ & 1.2 & $1.1-1.3^{*}$ & 1.2 & $1.1-1.3 *$ \\
\hline $\mathrm{HbA}_{1 \mathrm{c}} \mathrm{c}^{\mathrm{s}}$ & 1.1 & $1.0-1.2 *$ & 1.1 & $1.0-1.2$ \\
\hline \multicolumn{5}{|l|}{ CVD mortality } \\
\hline \multicolumn{5}{|l|}{ FPG (two slope spline) $)^{\mathrm{a}}$} \\
\hline$<5.1$ & 3.5 & $1.8-6.7^{*}$ & 4.0 & $2.1-7.6^{*}$ \\
\hline$>5.1$ & 1.3 & $1.1-1.4^{*}$ & 1.3 & $1.1-1.4^{*}$ \\
\hline $2 \mathrm{hPG}^{\mathrm{c}}$ & 1.2 & $1.1-1.4^{*}$ & 1.2 & $1.0-1.4^{*}$ \\
\hline $\mathrm{HbA}_{1 \mathrm{c}}{ }^{\mathrm{c}}$ & 1.2 & $1.1-1.4^{*}$ & 1.2 & $1.0-1.3 *$ \\
\hline
\end{tabular}

${ }^{\mathrm{a}}$ Data for FPG $<5.1 \mathrm{mmol} / 1$ are HR $(95 \% \mathrm{CI})$ per $1 \mathrm{SD}(0.7 \mathrm{mmol} / \mathrm{l})$ decrease in FPG below $5.1 \mathrm{mmol} / \mathrm{l}$; data for FPG $\geq 5.1 \mathrm{mmol} / \mathrm{lare} \mathrm{HR}(95 \%$ CI) per $1 \mathrm{SD}(0.7 \mathrm{mmol} / \mathrm{l})$ increase in FPG above $5.1 \mathrm{mmol} / \mathrm{l}$. SD based on whole population distribution

${ }^{\mathrm{b}}$ Adjusted for age, sex, history of CVD (angina, myocardial infarction or stroke), smoking (current or ex-smoker), diastolic blood pressure $(\mathrm{mmHg})$, waist-to-hip ratio, lipid-lowering medication use, total cholesterol $(\mathrm{mmol} / \mathrm{l})$ and triacylglycerol $(\mathrm{mmol} / \mathrm{l})$

${ }^{\mathrm{c}}$ Data for $2 \mathrm{hPG}$ and $\mathrm{HbA}_{1 \mathrm{c}}$ are HRs $(95 \% \mathrm{CI})$ per $1 \mathrm{SD}$ increase of the whole population distribution for $2 \mathrm{hPG}(2.2 \mathrm{mmol} / \mathrm{l}) \mathrm{and} \mathrm{HbA} / \mathrm{c}(0.4 \%)$, respectively

$* p<0.05$

cause mortality per SD (2.2 mmol/l) increase of $2 \mathrm{hPG}$ was greater in women (Table 3). For all-cause mortality, there were no significant interactions between $\mathrm{HbA}_{1 \mathrm{c}}$ and sex, age or history of CVD (data not shown). The relationships of FPG, $2 \mathrm{hPG}$ and $\mathrm{HbA}_{1 \mathrm{c}}$ with CVD mortality and of $2 \mathrm{hPG}$ with non-CVD mortality did not vary according to sex, age or history of CVD (data not shown).

Table 4 shows the results of simultaneous modelling of the glucose measures. The associations between $\mathrm{HbA}_{1 \mathrm{c}}$ and both all-cause and CVD mortality became non-significant with adjustment for FPG and 2hPG. Prediction of all-cause or CVD mortality by models with FPG alone or $2 \mathrm{hPG}$ alone was not significantly improved by adding $\mathrm{HbA}_{1 \mathrm{c}}$. FPG $<5.1 \mathrm{mmol} / 1$ remained significantly associated with all-cause and CVD mortality, but the association between FPG $\geq 5.1 \mathrm{mmo} / 1$ and these outcomes was attenuated, particularly after adjusting for $2 \mathrm{hPG}$. The latter was a significant predictor of all-cause mortality independent of

Table 3 Risk of all-cause mortality according to FPG and 2hPG in men and women without previously diagnosed diabetes - the AusDiab study

\begin{tabular}{|c|c|c|c|c|}
\hline \multirow[t]{2}{*}{ Blood glucose measure (per SD) $)^{\text {ac }}$} & \multicolumn{2}{|c|}{ Age-adjusted } & \multicolumn{2}{|c|}{ Multivariate-adjusted $^{\mathrm{b}}$} \\
\hline & HR & $95 \% \mathrm{CI}$ & HR & $95 \% \mathrm{CI}$ \\
\hline \multicolumn{5}{|l|}{ Women } \\
\hline \multicolumn{5}{|l|}{ FPG (two-slope spline) ${ }^{\mathrm{a}}$} \\
\hline$<5.1$ & 1.5 & $0.8-2.8$ & 1.5 & $0.8-2.7$ \\
\hline$>5.1$ & 1.2 & $1.0-1.3 *$ & 1.1 & $1.0-1.3$ \\
\hline $2 \mathrm{hPG}^{\mathrm{c}}$ & 1.3 & $1.2-1.5^{*}$ & 1.3 & $1.1-1.4^{*}$ \\
\hline \multicolumn{5}{|l|}{ Men } \\
\hline \multicolumn{5}{|l|}{ FPG (two-slope spline) ${ }^{\mathrm{a}}$} \\
\hline$<5.1$ & 4.5 & $2.4-8.5^{*}$ & 4.4 & $2.2-8.5^{*}$ \\
\hline$>5.1$ & 1.1 & $1.0-1.2$ & 1.1 & $1.0-1.2$ \\
\hline $2 \mathrm{hPG}^{\mathrm{c}}$ & 1.1 & $1.0-1.2$ & 1.1 & $1.0-1.2$ \\
\hline
\end{tabular}

${ }^{\text {a }}$ Data for FPG $<5.1 \mathrm{mmol} / 1$ are HR $(95 \% \mathrm{CI})$ per $1 \mathrm{SD}(0.7 \mathrm{mmol} / \mathrm{l})$ decrease in FPG below $5.1 \mathrm{mmol} / \mathrm{l}$; data for FPG $\geq 5.1 \mathrm{mmol} / \mathrm{l}$ are $\mathrm{HR}(95 \%$ $\mathrm{CI})$ per $1 \mathrm{SD}(0.7 \mathrm{mmol} / \mathrm{l})$ increase in FPG above $5.1 \mathrm{mmol} / \mathrm{l}$. SD based on whole population distribution

${ }^{\mathrm{b}}$ Adjusted for age, history of CVD (angina, myocardial infarction or stroke), smoking (current and ex-smoker), diastolic blood pressure (mmHg), waist-to-hip ratio, lipid-lowering medication use, total cholesterol $(\mathrm{mmol} / \mathrm{l})$ and triacylglycerol $(\mathrm{mmol} / \mathrm{l})$

${ }^{\mathrm{c}}$ Data for $2 \mathrm{hPG}$ are HR $(95 \% \mathrm{CI})$ per $1 \mathrm{SD}(2.2 \mathrm{mmol} / \mathrm{l})$ increase of the whole population distribution for $2 \mathrm{hPG}$

${ }^{*} p<0.05$ 
Table 4 Risk of all-cause and CVD mortality adjusted for FPG, $2 \mathrm{hPG}$ or $\mathrm{HbA}_{1 \mathrm{c}}$ in individuals without previously diagnosed diabetes - the AusDiab study

\begin{tabular}{|c|c|c|c|c|c|c|c|c|c|c|c|c|c|c|}
\hline \multirow{3}{*}{$\begin{array}{l}\text { Blood } \\
\text { glucose } \\
(\text { per SD) }\end{array}$} & \multicolumn{2}{|l|}{ Model 1} & \multicolumn{4}{|c|}{$\begin{array}{l}\text { Model 2-adding } \\
2 \mathrm{hPG}\end{array}$} & \multicolumn{4}{|c|}{$\begin{array}{l}\text { Model 3-adding } \\
\text { FPG }\end{array}$} & \multicolumn{4}{|c|}{$\begin{array}{l}\text { Model 4-adding } \\
\mathrm{HbA}_{1 \mathrm{c}}\end{array}$} \\
\hline & \multirow{2}{*}{$\begin{array}{l}\mathrm{HR} \\
(95 \% \mathrm{CI})\end{array}$} & \multirow{2}{*}{$\begin{array}{l}\text { c- } \\
\text { statistic }\end{array}$} & \multirow{2}{*}{$\begin{array}{l}\text { HR } \\
(95 \% \mathrm{CI})\end{array}$} & \multirow{2}{*}{$\begin{array}{l}\mathrm{c}- \\
\text { statistic }\end{array}$} & \multicolumn{2}{|c|}{ LR test ${ }^{\mathrm{a}}$} & \multirow{2}{*}{$\begin{array}{l}\mathrm{HR} \\
-(95 \% \mathrm{CI})\end{array}$} & \multirow{2}{*}{$\begin{array}{l}\text { c- } \\
\text { statistic }\end{array}$} & \multicolumn{2}{|c|}{ LR test ${ }^{\mathrm{a}}$} & \multirow{2}{*}{$\begin{array}{l}\text { HR } \\
(95 \% \mathrm{CI})\end{array}$} & \multirow{2}{*}{$\begin{array}{l}\mathrm{c}- \\
\text { statistic }\end{array}$} & \multicolumn{2}{|c|}{ LR test ${ }^{\mathrm{a}}$} \\
\hline & & & & & $x^{2}$ & $p$ value & & & $x^{2}$ & $p$ value & & & $x^{2}$ & $p$ value \\
\hline \multicolumn{15}{|c|}{$\begin{array}{l}\text { All-cause mortality } \\
\text { FPG }^{\text {b }}\end{array}$} \\
\hline$<5.1$ & $2.0(1.3-3.0)^{*}$ & 0.863 & $2.0(1.4-3.1)^{*}$ & 0.866 & 11.5 & $<0.001$ & - & - & - & - & $2.0(1.3-3.0)^{*}$ & 0.864 & 0.7 & 0.40 \\
\hline$\geq 5.1$ & $1.1(1.0-1.2) *$ & & $1.0(0.9-1.1)$ & & & & - & - & - & - & $1.1(0.9-1.2)$ & & & \\
\hline $2 \mathrm{hPG}^{\mathrm{c}}$ & $1.2(1.1-1.3) *$ & 0.865 & - & - & - & - & $1.2(1.1-1.3)^{*}$ & 0.866 & 9.0 & 0.01 & $1.2(1.1-1.3)^{*}$ & 0.865 & 0.11 & 0.74 \\
\hline $\mathrm{HbA}_{1 \mathrm{c}}{ }^{\mathrm{c}}$ & $1.1(1.0-1.2)$ & 0.862 & $1.0(0.9-1.1)$ & 0.865 & 9.9 & 0.002 & $1.1(0.9-1.2)$ & 0.864 & 8.0 & 0.02 & - & - & - & - \\
\hline \multicolumn{15}{|c|}{$\begin{array}{l}\text { CVD mortality } \\
\text { FPG }^{\mathrm{b}}\end{array}$} \\
\hline$<5.1$ & $4.0(2.1-7.6)^{*}$ & 0.935 & $4.1(2.2-7.8)^{*}$ & 0.936 & 1.3 & 0.26 & - & - & - & - & $4.1(2.1-7.7)^{*}$ & 0.935 & 0.03 & 0.86 \\
\hline$\geq 5.1$ & $1.3(1.1-1.4)^{*}$ & & $1.2(1.0-1.4)$ & & & & - & - & - & - & $1.3(1.0-1.6)^{*}$ & & & \\
\hline $2 \mathrm{hPG}^{\mathrm{c}}$ & $1.2(1.0-1.4)^{*}$ & 0.933 & - & - & - & - & $1.1(0.9-1.4)$ & 0.936 & 12.1 & 0.002 & $1.2(1.0-1.4)$ & 0.933 & 0.5 & 0.49 \\
\hline $\mathrm{HbA}_{1 \mathrm{c}}{ }^{\mathrm{c}}$ & $1.2(1.0-1.3)^{*}$ & 0.933 & $1.1(0.9-1.3)$ & 0.933 & 2.3 & 0.13 & $1.0(0.8-1.2)$ & 0.935 & 12.6 & 0.002 & - & - & - & - \\
\hline
\end{tabular}

Model 1, adjusted for age, sex, history of CVD (angina, myocardial infarction or stroke), smoking (current and ex-smoker), diastolic blood pressure $(\mathrm{mmHg})$, waist-to-hip ratio, lipid-lowering medication use, total cholesterol (mmol/l) and triacylglycerol (mmol/l)

Model 2, adjusted for model 1 plus $2 \mathrm{hPG}$

Model 3, adjusted for model 1 plus FPG

Model 4, adjusted for model 1 plus $\mathrm{HbA}_{1 \mathrm{c}}$

${ }^{a}$ Log-likelihood ratio test comparing a model with two glucose measures to a model with a single glucose measure

${ }^{\mathrm{b}}$ Data for FPG $<5.1 \mathrm{mmol} / \mathrm{l}$ are HR $(95 \% \mathrm{CI})$ per $1 \mathrm{SD}(0.7 \mathrm{mmol} / \mathrm{l})$ decrease in FPG below $5.1 \mathrm{mmol} / \mathrm{l}$; data for FPG $\geq 5.1 \mathrm{mmol} / 1 \mathrm{are} \mathrm{HR}(95 \%$ CI) per $1 \mathrm{SD}(0.7 \mathrm{mmol} / \mathrm{l})$ increase in $\mathrm{FPG}$ above $5.1 \mathrm{mmol} / \mathrm{l}$. SD based on whole population distribution

${ }^{\mathrm{c}}$ Data for $2 \mathrm{hPG}$ and $\mathrm{HbA}_{1 \mathrm{c}}$ are $\mathrm{HRs}(95 \% \mathrm{CI})$ per $1 \mathrm{SD}$ increase of the whole population distribution for $2 \mathrm{hPG}(2.2 \mathrm{mmol} / \mathrm{l})$ and $\mathrm{HbA} 1 \mathrm{c}(0.4 \%)$, respectively

$* p<0.05$

FPG and $\mathrm{HbA}_{1 \mathrm{c}}$, but the relationship between $2 \mathrm{hPG}$ and CVD mortality was attenuated by FPG. Entering $2 \mathrm{hPG}$ into models based on FPG alone or $\mathrm{HbA}_{1 \mathrm{c}}$ alone significantly improved the prediction of all-cause, but not of CVD mortality, whereas entering FPG into models based on $2 \mathrm{hPG}$ alone or $\mathrm{HbA}_{1 \mathrm{c}}$ alone significantly improved the prediction of all-cause and CVD mortality.

For individual risk discrimination, there was little difference between the three glucose indices in predicting all-cause and CVD mortality. Table 4 shows that the cstatistics were similar for multivariate-adjusted models containing any of $\mathrm{FPG}, 2 \mathrm{hPG}$ or $\mathrm{HbA}_{1 \mathrm{c}}$ alone. Moreover, the addition of more than one glucose measure into models containing a single glucose measure did not substantially improve the discriminative abilities of FPG, $2 \mathrm{hPG}$ or $\mathrm{HbA}_{1 \mathrm{c}}$, as indicated by small changes in the c-statistic.

The IDI and NRI results were in agreement with the cstatistic findings. For all-cause mortality, the relative IDIs (95\% CIs) for adding either FPG, $2 \mathrm{hPG}$ or $\mathrm{HbA}_{1 \mathrm{c}}$ to models with age, sex, history of CVD, smoking, diastolic blood pressure, waist-to-hip ratio, lipid-lowering medication use, total cholesterol and triacylglycerol were similar, namely: FPG $2.2 \%$ ( -0.05 to $11.6 \%), 2$ hPG $2.3 \%$ ( -0.7 to
10.4\%) and $\mathrm{HbA}_{1 \mathrm{c}} 0.3 \%$ (-0.6 to $5.5 \%$ ). For CVD mortality, the relative IDI $(95 \% \mathrm{CI})$ for FPG was $13.8 \%$ (2.3 to $43.6 \%$ ), which was greater than that for $2 \mathrm{hPG}(4.3 \%$ [-1.8 to $23.7 \%])$ or $\mathrm{HbA}_{1 \mathrm{c}}(3.0 \%$ [-1.1 to $\left.16.9 \%]\right)$. However, there were no meaningful differences between the three glucose indices in their ability to classify individuals across three 5 year CVD death risk categories ( 0 to $<10 \%, 10$ to $<20 \%$ and $\geq 20 \%$ ) beyond the classification provided by these traditional risk factors. The NRI $(95 \% \mathrm{CI})$ was $6.7 \%(-3.4 \%$ to $14.8 \%)$ for $\mathrm{FPG}$, $2.3 \%(-6.6 \%$ to $10.3 \%)$ for $2 \mathrm{hPG}, 0.1 \%(-6.1 \%$ to $9.0 \%)$ for $\mathrm{HbA}_{1 \mathrm{c}}$ and $5.7 \%(-19.8 \%$ to $15.0 \%)$ for all glucose measures added to the same model.

\section{Discussion}

The findings from this large contemporary populationbased prospective cohort of over 10,000 men and women aged $\geq 25$ years have shown that among individuals without diagnosed diabetes, FPG and $2 \mathrm{hPG}$, but not $\mathrm{HbA}_{1 \mathrm{c}}$ were significantly associated with an increased risk of all-cause mortality, and all three measures were significantly associ- 
ated with an increased risk of CVD mortality. The risks of all-cause and CVD mortality progressively increased throughout the range of $2 \mathrm{hPG}$ and $\mathrm{HbA}_{1 \mathrm{c}}$, but a J-shaped relationship was observed for FPG. To the best of our knowledge, this is the largest study using a range of techniques to evaluate, in the same study population, the nature and strength of the relationships between all these glucose measures and both all-cause and CVD mortality.

Our finding of a continuous graded relationship between 2hPG and CVD mortality concurs with some $[3,4,12]$ but not all studies [6, 10]. Balkau et al. [10] reported a J-shaped relationship for CVD mortality. Furthermore, others have reported a threshold relationship, where the risk of fatal and/or non-fatal CVD only increased in the upper range of the $2 \mathrm{hPG}$ distribution [6]. For all-cause mortality, we also observed a graded continuous relationship for $2 \mathrm{hPG}$. This contrasts with the findings of Balkau et al. [10] and DECODE [12], who both reported J-shaped relationships between $2 \mathrm{hPG}$ and all-cause mortality. Differences in study characteristics may explain the discordant findings. The DECODE study, a meta-analysis of individual data from different cohorts, combined different blood sample types and this may have introduced measurement imprecision [12]. Our study included men and women aged $\geq 25$ years and used a $75 \mathrm{~g}$ OGTT, whereas other findings were based on men only, [10] or used a $50 \mathrm{~g}$ OGTT [6].

The nature of the relationship between $\mathrm{HbA}_{1 \mathrm{c}}$ and both all-cause mortality and CVD in people without diagnosed diabetes has been reported in other observational studies [7, 16-18, 37, 38]. Several studies reported a consistent graded relationship between $\mathrm{HbA}_{1 \mathrm{c}}$ and both all-cause mortality $[16,18,37,38]$ and fatal and/or non-fatal CVD [16, 18]. In contrast, Selvin et al. [7] found that the risk of coronary heart disease only increased above an $\mathrm{HbA}_{1 \mathrm{c}}$ of $4.6 \%$. None of these studies adjusted for other glucose measures. Our study extends these observations by demonstrating that a graded continuous relationship between $\mathrm{HbA}_{1 \mathrm{c}}$ and both all-cause and CVD mortality diminished after adjusting for FPG or $2 \mathrm{hPG}$. This can be explained by the fact that $\mathrm{HbA}_{1 \mathrm{c}}$ reflects blood glucose concentration over the previous 2 to 3 months [13].

Low FPG, particularly in men, was associated with an increased risk of all-cause and CVD mortality. This supports several other studies [10-12, 39, 40], although different nadirs ranging from 3.3 to $5.2 \mathrm{mmol} / \mathrm{l}$ have been reported [40]. These differences may reflect varying study characteristics and methods. The physiological mechanism underlying this association is unclear. Although low fasting blood glucose may indicate poor general health [40], we found that even after excluding individuals who died in the first year (i.e. those people possibly terminally ill at baseline), individuals with a low FPG were still at risk of death from all causes or CVD.
This study also revealed that $2 \mathrm{hPG}$, rather than FPG or $\mathrm{HbA}_{1 \mathrm{c}}$, was significantly associated with non-CVD mortality, a finding consistent with other studies that have found abnormal glucose metabolism to be related to cancer mortality [41-43]. In our study it was not possible to specifically investigate the relationship between plasma glucose and cancer mortality, as the relatively short period of follow-up reduced the power to undertake this analysis. However, $61.3 \%$ of non-CVD deaths were attributable to malignant neoplasm. The mechanisms underlying the association between abnormal glucose metabolism and cancer are not fully understood. However, it is thought that abnormal glucose metabolism may increase tumour growth and cell proliferation through hyperinsulinaemia and systemic inflammatory responses $[44,45]$. It is thought that $2 \mathrm{hPG}$, rather than FPG, is more strongly linked to hyperinsulinaemia [13] and may therefore help to explain our findings of an association between 2hPG and non-CVD mortality.

Few studies have compared the predictive capabilities of all three measures in the same study population [19-22]. In the Rancho Bernardo Study [19], GHb was found to be a better predictor of CVD and ischaemic heart disease mortality than FPG or $2 \mathrm{hPG}$ in women only. In contrast, other studies found that post-load blood glucose was a better predictor of mortality and/or CVD outcomes than FPG or $\mathrm{HbA}_{1 \mathrm{c}}$ [20-22]. In our study, $\mathrm{HbA}_{1 \mathrm{c}}$ did not predict all-cause and CVD mortality independent of FPG or $2 \mathrm{hPG}$. When FPG and 2hPG were included in the same model, FPG $<5.1 \mathrm{mmol} / 1$ remained significantly associated with all-cause and CVD mortality, but the associations diminished for $F P G \geq 5.1 \mathrm{mmol} / 1$, and although $2 \mathrm{hPG}$ remained significantly associated with all-cause mortality, this was attenuated for CVD mortality.

Our study has extended these findings by also evaluating the discriminative ability of FPG, $2 \mathrm{hPG}$ and $\mathrm{HbA}_{1 \mathrm{c}}$ to identify individuals at higher risk of all-cause and CVD mortality. Although $2 \mathrm{hPG}$ had slightly superior discriminative ability for all-cause mortality than FPG and $\mathrm{HbA}_{1 \mathrm{c}}$, and FPG had slightly superior discriminative ability for CVD mortality than $2 \mathrm{hPG}$ and $\mathrm{HbA}_{1 \mathrm{c}}$, the actual differences in the c-statistics of these models were of a small magnitude $(<0.003)$. In addition, all measures displayed similar IDI estimates for all-cause mortality, and although the IDI estimate for CVD mortality was greater for FPG than for $2 \mathrm{hPG}$ and $\mathrm{HbA}_{1 \mathrm{c}}$, all measures displayed similar nonsignificant improvements in the NRI estimations. This therefore suggests that an OGTT adds only a small and possibly clinically unimportant amount of information on individual mortality risk discrimination over and above FPG and $\mathrm{HbA}_{1 \mathrm{c}}$.

Despite our findings of significant independent associations between both FPG and 2hPG and all-cause mortality, 
and between the three glucose variables FPG, $2 \mathrm{hPG}$ and $\mathrm{HbA}_{1 \mathrm{c}}$ and CVD mortality, the ability of blood glucose to classify individual risk was only modest when traditional risk factors such as prior CVD, smoking, blood pressure, hyperlipidaemia, lipid-lowering medication and abdominal adiposity were considered. This finding has been reported by others [21, 46]. The phenomenon of a significant independent risk factor not substantially improving individual risk classification is not uncommon, as such discrimination often requires very strong measures of association [47]. Nevertheless, our findings do indicate that glucose measures are important in characterising population risk of mortality even among individuals without diagnosed diabetes, and suggest that intermediate hyperglycaemia may play a role in the development of CVD.

The findings of this study should be interpreted in the context of its limitations. The response rate of $37 \%$ of those eligible for testing may indicate that the study cohort was not fully representative of the Australian adult population. However, differences between responders and non-responders are unlikely to impact on the associations between blood glucose and mortality. A single $75 \mathrm{~g}$ OGTT was used to measure FPG and $2 \mathrm{hPG}$. These measures are subject to within-person variability [48], and this may have introduced some imprecision and regression dilution bias, leading to underestimation of the relative risk of mortality. It is also possible that storage of samples had an effect on $\mathrm{HbA}_{1 \mathrm{c}}$ values, but we could find no evidence for such an effect. Furthermore, the relatively short follow-up period may have reduced the power to detect a significant association between $\mathrm{HbA}_{1 \mathrm{c}}$ and all-cause mortality, which showed borderline significance. The findings from observational studies such as ours, while identifying population-based associations, need to be supported by physiological experiments and clinical trials to help unravel the effects different indices of glycaemia have on CVD and mortality.

In summary, we compared three glycaemic indices with respect to all-cause and CVD mortality in people without diagnosed diabetes. The results indicate that $2 \mathrm{hPG}$ and $\mathrm{FPG}$, rather than $\mathrm{HbA}_{1 \mathrm{c}}$, were important independent predictors of all-cause and CVD mortality. Although these glucose measures did not substantially improve individual risk identification, the findings nevertheless highlight the potentially important role of glycaemia in the development of CVD and all-cause mortality in the general population.

Acknowledgements $\quad$ E. L. M. Barr is supported by a National Health and Medical Research Council (NHMRC; 379305)/National Heart Foundation Australia (PP 05M 2346) joint postgraduate scholarship. The AusDiab Study is supported by an NHMRC project grant (233200) and in-kind support from the Australian Institute of Health and Welfare, who provided the mortality data. In addition, we are most grateful to the following for their support of the study: The Commonwealth Department of Health and Aged Care, Abbott Australasia, Alphapharm, AstraZeneca,
Aventis Pharmaceutical, Bristol-Myers Squibb Pharmaceuticals, Eli Lilly (Aust), GlaxoSmithKline, Janssen-Cilag (Aust), Merck Lipha, Merck Sharp \& Dohme (Aust), Novartis Pharmaceutical (Aust), Novo Nordisk Pharmaceutical, Pharmacia and Upjohn, Pfizer, Roche Diagnostics, Sanofi Synthelabo (Aust), Servier Laboratories (Aust), BioRad Laboratories, HITECH Pathology, the Australian Kidney Foundation, Diabetes Australia, Diabetes Australia (Northern Territory), Queensland Health, South Australian Department of Human Services, Tasmanian Department of Health and Human Services, Territory Health Services and Victorian Department of Human Services, and Health Department of Western Australia. We thank B. Balkau for statistical advice. Also, we thank our study staff and study participants for their hard work and cooperation.

Duality of interest The authors declare that there is no duality of interest associated with this manuscript.

\section{References}

1. The DECODE study group on behalf of the European Diabetes Epidemiology Group (2001) Glucose tolerance and cardiovascular mortality: comparison of fasting and 2-hour diagnostic criteria. Arch Intern Med 161:397-405

2. Barr EL, Zimmet PZ, Welborn TA et al (2007) Risk of cardiovascular and all-cause mortality in individuals with diabetes mellitus, impaired fasting glucose, and impaired glucose tolerance: the Australian Diabetes, Obesity, and Lifestyle Study (AusDiab). Circulation 116:151-157

3. Coutinho M, Gerstein HC, Wang Y, Yusuf S (1999) The relationship between glucose and incident cardiovascular events. A metaregression analysis of published data from 20 studies of 95,783 individuals followed for 12.4 years. Diabetes Care 22:233-240

4. Levitan EB, Song Y, Ford ES, Liu S (2004) Is nondiabetic hyperglycemia a risk factor for cardiovascular disease? A metaanalysis of prospective studies. Arch Intern Med 164:2147-2155

5. National Diabetes Data Group (1979) Classification and diagnosis of diabetes mellitus and other categories of glucose intolerance. Diabetes 28:1039-1057

6. Brunner EJ, Shipley MJ, Witte DR, Fuller JH, Marmot MG (2006) Relation between blood glucose and coronary mortality over 33 years in the Whitehall Study. Diabetes Care 29:26-31

7. Selvin E, Coresh J, Golden SH, Brancati FL, Folsom AR, Steffes MW (2005) Glycaemic control and coronary heart disease risk in persons with and without diabetes: the atherosclerosis risk in communities study. Arch Intern Med 165:1910-1916

8. Lawes CM, Parag V, Bennett DA et al (2004) Blood glucose and risk of cardiovascular disease in the Asia Pacific region. Diabetes Care 27:2836-2842

9. Port SC, Goodarzi MO, Boyle NG, Jennrich RI (2005) Blood glucose: a strong risk factor for mortality in nondiabetic patients with cardiovascular disease. Am Heart J 150:209-214

10. Balkau B, Bertrais S, Ducimetiere P, Eschwege E (1999) Is there a glycemic threshold for mortality risk? Diabetes Care 22:696-699

11. Wei M, Gibbons LW, Mitchell TL, Kampert JB, Stern MP, Blair SN (2000) Low fasting plasma glucose level as a predictor of cardiovascular disease and all-cause mortality. Circulation 101:2047-2052

12. The DECODE study group on behalf of the European Diabetes Epidemiology Group (2003) Is the current definition for diabetes relevant to mortality risk from all causes and cardiovascular and noncardiovascular diseases? Diabetes Care 26:688-696

13. Goldstein DE, Little RR, Lorenz RA, Malone JI, Nathan DM, Peterson CM (2004) Tests of glycemia in diabetes. Diabetes Care 27(Suppl 1):S91-S93 
14. Simons LA, Friedlander Y, McCallum J, Simons J (2000) Fasting plasma glucose in non-diabetic elderly women predicts increased all-causes mortality and coronary heart disease risk. Aust $\mathrm{N} \mathrm{Z} \mathrm{J}$ Med 30:41-47

15. Qiao Q, Pyorala K, Pyorala M et al (2002) Two-hour glucose is a better risk predictor for incident coronary heart disease and cardiovascular mortality than fasting glucose. Eur Heart J 23:12671275

16. Gao L, Matthews FE, Sargeant LA, Brayne C (2008) An investigation of the population impact of variation in $\mathrm{HbAlc}$ levels in older people in England and Wales: from a population based multi-centre longitudinal study. BMC Public Health 8:54

17. Nakanishi S, Yamada M, Hattori N, Suzuki G (2005) Relationship between $\mathrm{HbA}(1) \mathrm{c}$ and mortality in a Japanese population. Diabetologia 48:230-234

18. Khaw KT, Wareham N, Bingham S, Luben R, Welch A, Day N (2004) Association of hemoglobin A1c with cardiovascular disease and mortality in adults: the European prospective investigation into cancer in Norfolk. Ann Intern Med 141:413-420

19. Park S, Barrett-Connor E, Wingard DL, Shan J, Edelstein S (1996) $\mathrm{GHb}$ is a better predictor of cardiovascular disease than fasting or postchallenge plasma glucose in women without diabetes. The Rancho Bernardo Study. Diabetes Care 19:450-456

20. de Vegt F, Dekker JM, Ruhe HG et al (1999) Hyperglycaemia is associated with all-cause and cardiovascular mortality in the Hoorn population: the Hoorn Study. Diabetologia 42:926-931

21. Meigs JB, Nathan DM, D’Agostino RB Sr, Wilson PW (2002) Fasting and postchallenge glycemia and cardiovascular disease risk: the Framingham Offspring Study. Diabetes Care 25:1845-1850

22. Qiao Q, Dekker JM, de Vegt F et al (2004) Two prospective studies found that elevated 2-hr glucose predicted male mortality independent of fasting glucose and HbA1c. J Clin Epidemiol 57:590-596

23. Dunstan DW, Zimmet PZ, Welborn TA et al (2002) The Australian Diabetes, Obesity and Lifestyle Study (AusDiab) methods and response rates. Diabetes Res Clin Pract 57:119-129

24. Briganti EM, Shaw JE, Chadban SJ et al (2003) Untreated hypertension among Australian adults: the 1999-2000 Australian Diabetes, Obesity and Lifestyle Study (AusDiab). Med J Aust 179:135-139

25. Dalton M, Cameron AJ, Zimmet PZ et al (2003) Waist circumference, waist-hip ratio and body mass index and their correlation with cardiovascular disease risk factors in Australian adults. J Intern Med 254:555-563

26. Jones W, Scott J, Leary S et al (2004) Stability of whole blood at -70 degrees $\mathrm{C}$ for measurement of hemoglobin $\mathrm{A}(1 \mathrm{c})$ in healthy individuals. Clin Chem 50:2460-2461

27. Magliano D, Liew D, Pater H et al (2003) Accuracy of the Australian National Death Index: comparison with adjudicated fatal outcomes among Australian participants in the Long-term Intervention with Pravastatin in Ischaemic Disease (LIPID) study. Aust N Z J Public Health 27:649-653

28. The Expert Committee on the Diagnosis and Classification of Diabetes Mellitus (2003) Follow-up report on the diagnosis of diabetes mellitus. Diabetes Care 26:3160-3167

29. The World Health Organization (1999) Definition, diagnosis and classification of diabetes mellitus and its complications. part 1: diagnosis and classification of diabetes mellitus. Department of Noncommunicable Disease Surveillance, Geneva

30. The World Health Organization and International Diabetes Federation (2006) Definition and diagnosis of diabetes mellitus and intermediate hyperglycaemia. WHO, Geneva

31. Greenland S (1989) Modeling and variable selection in epidemiologic analysis. Am J Public Health 79:340-349
32. Akaike H (1974) A new look at the statistical model identification. IEEE Trans Automat Contr 19:716-723

33. Glantz S, Slinker B (1990) Primer of applied regression and analysis of variance. McGraw-Hill, New York

34. Pencina MJ, D'Agostino RB Sr, D'Agostino RB Jr, Vasan RS (2008) Evaluating the added predictive ability of a new marker: from area under the ROC curve to reclassification and beyond. Stat Med 27:157-172

35. Graham I, Atar D, Borch-Johnsen K et al (2007) European guidelines on cardiovascular disease prevention in clinical practice: executive summary. Fourth Joint Task Force of the European Society of Cardiology and other societies on cardiovascular disease prevention in clinical practice (constituted by representatives of nine societies and by invited experts). Eur $\mathrm{J}$ Cardiovasc Prev Rehabil 14(Suppl 2):E1-E40

36. Pearson TA, Blair SN, Daniels SR et al (2002) AHA guidelines for primary prevention of cardiovascular disease and stroke: 2002 update: consensus panel guide to comprehensive risk reduction for adult patients without coronary or other atherosclerotic vascular diseases. American Heart Association Science Advisory and Coordinating Committee. Circulation 106:388-391

37. Brewer N, Wright CS, Travier N et al (2008) A New Zealand linkage study examining the associations between A1C concentration and mortality. Diabetes Care 31:1144-1149

38. Levitan EB, Liu S, Stampfer MJ et al (2008) HbA(1c) measured in stored erythrocytes and mortality rate among middle-aged and older women. Diabetologia 51:267-275

39. Wen CP, Cheng TY, Tsai SP, Hsu HL, Wang SL (2005) Increased mortality risks of pre-diabetes (impaired fasting glucose) in Taiwan. Diabetes Care 28:2756-2761

40. Wandell PE, Theobald H (2007) The association between low fasting blood glucose value and mortality. Curr Diabetes Rev 3:274-279

41. Balkau B, Shipley M, Jarrett RJ et al (1998) High blood glucose concentration is a risk factor for mortality in middle-aged nondiabetic men. 20-year follow-up in the Whitehall Study, the Paris Prospective Study, and the Helsinki Policemen Study. Diabetes Care 21:360-367

42. Levine W, Dyer AR, Shekelle RB, Schoenberger JA, Stamler J (1990) Post-load plasma glucose and cancer mortality in middleaged men and women. 12-year follow-up findings of the Chicago Heart Association Detection Project in Industry. Am J Epidemiol 131:254-262

43. Saydah SH, Loria CM, Eberhardt MS, Brancati FL (2003) Abnormal glucose tolerance and the risk of cancer death in the United States. Am J Epidemiol 157:1092-1100

44. Giovannucci E (2001) Insulin, insulin-like growth factors and colon cancer: a review of the evidence. J Nutr 131:3109S-3120S

45. Renehan AG, Zwahlen M, Minder C, O’Dwyer ST, Shalet SM, Egger M (2004) Insulin-like growth factor (IGF)-I, IGF binding protein-3, and cancer risk: systematic review and meta-regression analysis. Lancet 363:1346-1353

46. Simmons RK, Sharp S, Boekholdt M et al (2008) Evaluation of the Framingham risk score in the European prospective investigation of cancer-Norfolk Cohort. Does adding glycated hemoglobin improve the prediction of coronary heart disease events? Arch Intern Med 168:1209-1216

47. Pepe MS, Janes H, Longton G, Leisenring W, Newcomb P (2004) Limitations of the odds ratio in gauging the performance of a diagnostic, prognostic, or screening marker. Am J Epidemiol 159:882-890

48. Selvin E, Crainiceanu CM, Brancati FL, Coresh J (2007) Shortterm variability in measures of glycemia and implications for the classification of diabetes. Arch Intern Med 167:1545-1551 